\title{
Effect of Teamwork on Employee Performance in High-Tech Engineering SMEs of Pakistan: A Moderating Role of Supervisor Support
}

\author{
Muhammad Shahnawaz Adil *
}

Kamal Bin Ab Hamid ${ }^{\dagger}$

\begin{abstract}
Measuring employee performance of high-tech engineering small and medium-sized enterprises (SMEs) of a developing country is meagre in the literature of organizational studies. Therefore, this paper analyzes a) the effect of teamwork on employee performance; and b) how supervisor support moderates the relationship between teamwork and employee performance. Using a cross-sectional survey in a non-contrived field-study setting, a useable sample of 273 responses is drawn from different high-tech engineering SMEs of Karachi (Pakistan). Common method variance bias is tested using Harman single factor and common latent factor methods. The measurement model demonstrates good internal consistency reliability, convergent and discriminant validity. Hypotheses are tested using variance-based partial least square structural equation modeling technique. PLS predict algorithm suggests high out-of-the sample predictive validity of the structural model. The results show that teamwork has a significant effect on employee performance and supervisor support moderates the positive relationship between teamwork and employee performance such that an increase in supervisor support strengthens the positive relationship between teamwork and employee performance. The findings suggest that the management of SMEs should institutionalize such working practices which could reinforce the culture of teamwork for the managerial employees. Moreover, it is also essential for the management to emphasize more on providing meaningful supervisor support to all managerial employees because it would certainly strengthen the relationship between teamwork and employee performance. This study extends generalizability of the positive relationship between teamwork and employee performance to the high-tech engineering SMEs of Pakistan. Limitations and directions for future studies are also discussed.
\end{abstract}

Keywords: Teamwork; employee performance; supervisor support; SMEs; Pakistan.

\section{Introduction}

In organizational studies, improving employee performance has been a complex phenomenon which has attracted tremendous attention from academicians and practitioners during the past couple of decades. In particular, literature has shown a recent interest in the competitive advantage of small and medium enterprise (SMEs) (Falahat, Ramayah, Soto-Acosta,

\footnotetext{
${ }^{*}$ COB-School of Business Management, Universiti Utara Malaysia (UUM), Sintok, Malaysia.

Department of Business Administration, IQRA University, Karachi, Pakistan. Email: adil.s@iuk.edu.pk

${ }^{\dagger}$ COB-School of Business Management, Universiti Utara Malaysia (UUM), Sintok, Malaysia.

Email: abkamal@uum.edu.my
} 
\& Lee, 2020). One of the primary reasons is the strategic thrust of the top management of a SME that intends to seek a competitive edge faster and better than their traditional and non-traditional rival firms. Once the organization has successfully managed to gain a competitive advantage, the next goal remains to sustain its competitive advantage by focusing on their basis of competition such as assets, intellectual capital, relationships etc. Moreover, decision on addressing specific marketplaces for the products and/or services as well as adequate product-market selection also play key roles in sustaining its competitive advantage (Porter, 2008).

Keeping in view that both gaining and sustaining the competitive advantage are equally important (Porter \& Guth, 2012), it is generally observed that few business organizations are either customer-centric or competitor-centric, whereas a few organizations are marketdriven which tend to give equal importance to both customers and competitors. These market-driven firms take an edge over their counterparts in the sense that they continually strive to work on creative ideas for the improvement of their products and/or services. Besides, organizational resources, lucrative market opportunities, location of the business and employees having high self-efficacy significantly contribute in improving the overall performance of the organization that could eventually lead to sustain its competitive advantage (Porter, 2008).

In fact, the working practices of an organization primarily portray the extent to which it is serious towards improving employee's performance. For instance, with the advent of contemporary information and design technologies (ICTs) in the manufacturing processes, design and engineering firms have to choose from any one of the two different strategic choices: a) adopt better technology to improve working practices or b) continue the way they are operating perhaps since the inception of their business. Because of their inability to respond to the needed changes in their business on or before the time, these organizations usually suffer from complacency and later on, 'boiled-frog' syndrome. It means that less-adaptive/agile firms are increasingly exposed to a series of alarming situations for an immediate change (Adil \& Awais, 2016), however, due to their complacent behavior, they are unable to sense the potential disaster in their business due to subtle change and ultimately, they face financial distress.

With the help of two examples, Sull (2005) has elucidated that why good companies run out of the business. According to him, one of the four reasons of business failures is when the processes become routines and the organization seems reluctant to invest time in seriously improving its working processes with review to face changing market and customer needs. One of these changing demands is the use of artificial intelligence (AI) routines and algorithms in business processes in order to create a competitive set of value propositions to its customers faster and better than rival firms. More precisely, high-tech engineering SMEs need to realize the significance of digital networks and algorithms which are sparingly woven into the fabric of the enterprise thus, AI substantially affects corporate strategy, business operations, and competition.

Besides, Hagiu and Wright (2020) cautioned that for-profit organizations generally put major emphasis on collecting maximum-possible data about their customers assuming that these huge sum of data will help them better mine business insights so that they could attract more customers thus, data could help them gain a sustainable competitive advantage. 
However, with the passage of time they start to learn that this was a major misconception. It is attributed to the fact that these firms need to assess the extent to which data-enabled learning is sustainable which could ultimately reinforce them to gaining or sustaining a competitive advantage. More precisely, companies must need to understand the proportion of the value added by these huge sum of customer data than the value added by their present product and /or service offerings. In short, high-tech engineering SMEs ought to realize the importance of gaining bulk amount of their customers' data with a profound belief that data can help them create a competitive advantage, however, it is equally important to maintain such organizational culture in which employees are comfortable enough to better perform for the goods of the organization.

Very recently, while contending existing ways of measuring organizational culture, Corritore, Goldberg, and Srivastava (2020) introduced a new way in which there is a need to measure organizational culture based on the type of language employees used about their organization in electronic communication such as emails, Slack messages, and Glassdoor postings. In short, it seems easy to sense an organizational culture, however, it is very difficult to measure. In today's era, the best organizational culture is the one which not only encourages diversity amid its members to drive creativity and innovation but also it is anchored by common beliefs shared among them.

In response to above-mentioned new directions, we build an argument here that teamwork is an important organizational practice which can enhance employee performance. Undoubtedly, numerous literature is available which has established a theoretical relationship between the two variables however, it is yet to know any empirical evidence of the said relationship specifically in the context of high-tech engineering SMEs of a developing country such as Pakistan. Besides, literature suggests that supervisor support has positive effect on employee performance indicating that employees are more likely to perform well in case if they receive tangible and/or intangible support from their supervisors. Nevertheless, a question that remains unanswered is whether supervisor support either strengthens or weakens the positive relationship between teamwork and employee performance.

This study in the chosen social context is important because it presents a unique case for empirical examination in Karachi. Despite the fact that Karachi is the largest commercial hub and the first sea port of Pakistan which provides domestic and multinational firms with a number of lucrative business opportunities, high-tech engineering SMEs of Karachi (Pakistan) is an understudied area in which there is a dearth of knowledge about the reciprocal multivariate relationship between teamwork, employee performance, and supervisor support in one study. Besides, the effect of organizational support on employee performance is well established din the literature (Rhoades \& Eisenberger, 2002), however, the effect of specific type of organizational support such as supervisor support on employee performance is still unclear (Chen et al., 2019) especially in the context of SMEs of a developing country. Therefore, the purpose of this quantitative study is to analyze the effect of teamwork on employee performance and how this relationship is moderated by supervisor support. 


\section{Theoretical Background \& Development of Hypotheses}

\section{Teamwork and Employee Performance}

Teamwork is an integral aspect of an organizational life cycle as well as a prominent feature of modern organizations (Mijakoski et al., 2018). One of the key features of a team is that "members working interdependently and being jointly accountable for performance goals" (Ancona, 1996). For a business organization, people working in teams could possibly instigate useful ideas to optimize manufacturing performance for instance, lower down the operational manufacturing costs, better innovative product time savings, better service quality and flexibility, and a faster route to gain competitive advantage (Adil, 2015; Porter, 2008). However, recent literature has opined that leadership behaviour in promoting and championing a change initiative plays a substantial role in observing organizational overall effectiveness (Adil, 2014) which inculcates an organizational culture to strive for high performance work system (HPWS) by instilling the vision and organizational values. As stated earlier manufacturing organizations could be aware of the state-of-the-art ICTs but they are unable to allocate time in adapting these new technologies. No doubt, these new technologies will demand to introduce new working practices in the organization to ensure its survival. Developing a culture of teamwork is one of the required changes because its ability to provide opportunities for employees to share their creative ideas.

Employee performance reflects an occupational behavior which should be consistent with core objectives and values of the organization. It is generally observed when employees start to contribute in meeting organizational goals (Mulki, Caemmerer, \& Heggde, 2015). In other words, task performance represents a worker's ability and personal drive to work harder and better to meet organizational objectives on time. In organizational psychology, the employee's efforts serve as the input to the organizational system which is observed in the form of performance as output. No doubt, hard work may be characterized in terms of delivering desired work output on time. On the same lines, Jaramillo, Ladik, Marshall, and Mulki (2007) has also concluded that successful performance strongly depends on employee's hard work. Besides, Rapp, Ahearne, Mathieu, and Schillewaert (2006) have also concluded that efforts are positively related with performance of employees.

The construct of the quality of teamwork represents a comprehensive framework to assess the extent to which team members collaborate with each other. In organizational context, teamwork involves multiple employees who not only work together but also they are at the verge of potential disagreements with other team member. Therefore, teamwork is considered as a complex phenomenon and Hoegl and Parboteeah (2007) have conceptualized that teamwork is a higher-order construct. This aspect seems valid in the context of the manufacturing and engineering firms where teamwork plays an integral part in organizational hierarchy. They identified that there are six dimensions to observe quality of teamwork namely, vertical and lateral communication between team members, supervisors and project steering committee; improved coordinating mechanisms; appropriate balance of contribution from each of the team members; peer assistance, when need arises; consolidated efforts; and social interaction within and between teams. The underlying proposition is that a high degree of quality of teamwork is usually experienced among those teams which 
practice these afore-mentioned six facets. Therefore, these six factors collectively construct a higher-order latent variable i.e. high-quality teamwork.

Moreover, at one side where improving teamwork quality poses a great challenge and pressure on its members as well as project steering committee, on the other side it is very important for team members not to condone the importance of knowledge sharing with review to achieve better quality of work while being within time and resource constraints (Hauptman \& Hirji, 1996). Literature also suggests some other characteristics of effective teams such as team members should consult their individual activities with peers in order to improve its effective and efficient output on time and they also ought to function in such a manner that all of them could contribute with their best performance (Seers, 1989).

Furthermore, other authors have maintained that teams can better perform if they not only believe but also reciprocate efforts and peer support in resolving team issues to improve task performance and enjoy in exercising work ethics for better performance and cultivate useful organization of teams where their members strive to keep up the morale of one another (Gully, Devine, \& Whitney, 1995) and team knowledge. More specifically, teamwork significantly plays a central role for creativity in innovative projects (Hoegl \& Parboteeah, 2007) e.g. product designs (Kichuk \& Wiesner, 1997) as well as organizational performance. Similarly, other authors (Ahmad, Manzoor, et al., 2017) have also found that teamwork enhances employee morale and productivity. Thus, the following hypothesis is posited:

\section{$H_{1}$ : Teamwork has a positive effect on employee performance.}

\section{Moderating Role of Supervisor Support between Teamwork and Employee Performance}

Organizational support theory (Eisenberger, Huntington, Hutchison, \& Sowa, 1986) argues that employees tend to perform better when they sense the organizational care, attachment and support. Teams working in an effective learning organization tend to perform better than those teams which work in less innovative settings (Andrews \& Smits, 2019). The importance of teamwork has been highlighted in the literature (Hughes et al., 2016). Wayne, Shore, and Liden (1997) have found that the perception of supervisor support has been an integral part for both managerial and non-managerial employees in an organization. Furthermore, few authors have argued that there is a positive relationship between perceived organizational support and the extra-role behavior of both managerial and non-managerial employees. Consistent with the organizational support theory, Masterson (2001) found that social exchange is reciprocal in nature where subordinates intend to reciprocate constructive action they received from their supervisor in the form of their better performance.

In the context of service organization, these employees who are pretty much satisfied with the supervisor support they normally tend to satisfy their customers. This is a trickledown effect of the supervisor support in further improving employee performance. Similarly, Bell and Menguc (2002) found that customers rated relatively high to those service employees who receive better support from their line managers or supervisors. Moreover, Tepper and Taylor (2003) extended that supervisors who perceived that the organization 
had treated them fairly could return the same trust and confidence and fairness in treating subordinates. Thus, when a subordinates start to perceive that their supervisor treat them well as per the organizational policies and above all, ethically and morally with organizational justice, these individuals tend to exhibit various positive organizational outcomes such as organizational identification by improving their genuine ownership with organizational assets and reputation, reciprocation of additional work tasks towards organizational growth regardless even if they need to work beyond their duty hours, and above all, every possible efforts to maximize their occupational learning in workplace to better perform routine obligations.

Likewise a meta-analytical review (Dinh et al., 2020), the effect of organizational support on employee performance is well established in the literature (Rhoades \& Eisenberger, 2002), however, the effect of specific type of organizational support such as supervisor support on employee performance is still unclear (Chen et al., 2019). In short, it can be concluded that supervisor support further increases the efforts of a team for better task performance. Hence, the following hypothesis is suggested:

$\mathrm{H}_{2}$ : Supervisor support moderates the relationship between teamwork and employee performance such that an increase in supervisor support would strengthen the positive relationship between teamwork and employee performance.

Figure 1

Conceptual Framework

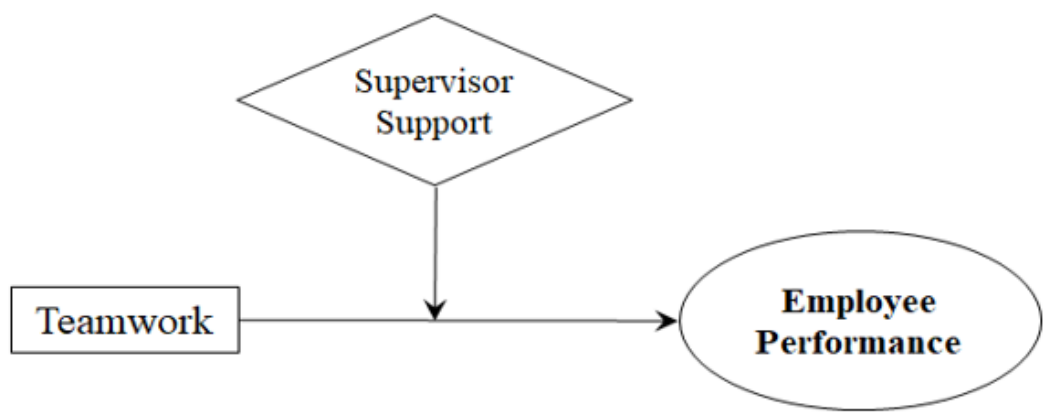

\section{Method}

\section{Sample and Procedures}

The unit of analysis of this study was the individuals working in the high-tech engineering SMEs of Karachi, Pakistan. A total of 510 survey questionnaires were distributed using a non-probability convenience sampling technique, however, only 360 responses was received. The response rate was 70.5 percent. The data were reduced to 273 useable responses after eliminating 87 outliers. Table 1 provides a detailed account of the useable sample $(\mathrm{n}=$ $273)$. 
Table 1

Descriptive Analysis $(\mathrm{n}=273)$

\begin{tabular}{llcc}
\hline Demographic Variables & Characteristics & Frequency & Percent \\
\hline Gender & Male & 234 & 85.7 \\
& Female & 39 & 14.3 \\
Age (in years) & Below 25 Years & 25 & 9.2 \\
& $25-30$ & 69 & 25.3 \\
& $31-35$ & 62 & 22.7 \\
& $36-40$ & 38 & 13.9 \\
& $41-45$ & 42 & 15.4 \\
& $46-50$ & 22 & 8.1 \\
& above 51 Years & 15 & 5.5 \\
& Bachelors & 115 & 42.1 \\
& Masters & 129 & 47.3 \\
& MPhil/MS & 14 & 5.1 \\
& Ph.D. & 4 & 1.5 \\
& Others & 11 & 4 \\
& Supervisor & 128 & 46.9 \\
& Middle-Management & 107 & 39.2 \\
& Senior Management & 32 & 11.7 \\
& Member of the Board & 6 & 2.2 \\
& Less than 5 & 59 & 21.6 \\
& 5 to 10 & 105 & 38.5 \\
& 10 to 15 & 45 & 16.5 \\
& 15 and 20 & 25 & 9.2 \\
& Over 20 years & 39 & 14.3 \\
\hline
\end{tabular}

\section{Measures}

\section{Teamwork (Predictor)}

To measure 'Teamwork', five items were adapted from Glaser, Zamanou, and Hacker (1987). One sample item states "People I work with are direct and honest with each other". This scale was measured on a five-point Likert type scale ranging from $1=$ "To a very little extent" to $5=$ "To a very great extent". Cronbach alpha was 0.79 .

\section{Supervisor Support (Moderator)}

To measure 'Supervisor Support', five items were adapted from Glaser et al. (1987). One sample item reads "Job requirements are made clear by my supervisor". This scale was measured on a five-point Likert type scale ranging from $1=$ "To a very little extent" to 5 $=$ "To a very great extent". Cronbach alpha was 0.81 .

\section{Employee Performance (Outcome)}

To measure 'Employee Performance', five items were adapted from Teclemichael Tessema and Soeters (2006). One sample item states "My performance is better than that of my colleagues with similar qualifications". This scale was measured on a five-point Likert type scale ranging from $1=$ "Strongly disagree" to $5=$ "Strongly agree". Cronbach alpha was 0.70 . 


\section{Analysis and Results}

The data analysis of this empirical study involves the following stages. First, the potential presence of common method variance bias is tested. Second, a measurement model is constructed to determine the validity and reliability of the three latent constructs. Finally, hypotheses are tested using PLS-SEM with a non-parametric bootstrapping method. Moreover, a simple slop analysis is performed to illustrate the interaction effect in case of a statistically significant moderation effect.

\section{Common Method Variance (CMV) Bias}

In this study, it was imperative to test the potential presence of CMV bias before data analysis because responses were collected from only one source (Reio Jr, 2010). We performed two tests to determine CMV bias: using Harman's single factor test in SPSS version 25 and the common latent factor test in AMOS version 22.

In Harman single factor test, all 15 Likert-type scale items were converged onto a single unrotated factor and it was noted that the single factor shared over 30.2 percent of the total variance which is less than 50 percent threshold value (Chaubey, Sahoo, \& Khatri, 2019) which indicates that the CMV bias was not a problem in this study.

Moreover, we also used common latent factor (CLF) method in AMOS to determine the potential issue of CMV bias in the dataset. In this method, the standardized estimates with and without the common latent factor are compared. We found no major discrepancy between the two sets of estimates because all standardized estimates were less than $|0.20|$. It led us to conclude that the CMV bias was not a problem (Dixon, Weeks, Boland Jr, \& Gaskin, 2019). Based on the findings of both Harman's and CLF methods, this study continued with the development of a measurement model.

\section{Measurement Model}

A measurement model is developed in SmartPLS version 3.2.8 (Ringle, Wende, \& Becker, 2015) to establish the relationship between observed and latent variables by assessing the convergent validity, discriminant validity and internal consistency reliability of teamwork, supervisor support and employee performance. This process is necessary before developing a structural model for hypothesis testing (Andersson \& Bateman, 1997; Hair, Black, Babin, Anderson, \& Tatham, 2019). Table 2 shows that the outer loading of each indicator item is in excess of 0.708 which implies that "...the variance shared between the construct and its indicator is larger than the measurement error variance" (Hair Jr, Hult, Ringle, \& Sarstedt, 2017).

The convergent validity and construct reliability were estimated by using average variance extracted (AVE) and composite reliability (CR) respectively. In contrast with conventional Cronbach's coefficient alpha, CR is a better reliability statistic because it measures the overall reliability of a collection of heterogeneous but similar items (Adil, 2016; Lin \& Lee, 2004; Molina, Lloréns-Montes, \& Ruiz-Moreno, 2007). The CR and roh_A values are greater than the cut-off value of 0.70 suggesting that all three latent variables demonstrate 
very good internal consistency reliability. Moreover, the AVE of each of the three constructs is greater than 0.50 showing a good convergent validity (Hair et al., 2019; Hair et al., 2017). Besides, the inner variance inflation factor (VIF) values of both exogenous latent variables are less than the stringent criterion of 3.3 (Hair Jr et al., 2017) indicating that there is no manifestation of pathological collinearity (Kock, 2015) or vertical collinearity issues in the measurement model.

Table 2

Construct Reliability and Convergent Validity $(\mathrm{n}=273)$

\begin{tabular}{lccccccc}
\hline Latent Variable & Indicators & Loadings & Alpha & roh_A & CR & AVE & VIF \\
\hline Employee Performance & EP4 & 0.877 & 0.700 & 0.700 & 0.870 & 0.770 & - \\
& EP5 & 0.874 & & & & & \\
Supervisor Support & SS1 & 0.749 & 0.820 & 0.830 & 0.870 & 0.570 & 1.570 \\
& SS2 & 0.770 & & & & & \\
& SS3 & 0.720 & & & & & \\
& SS4 & 0.813 & & & & & \\
Teamwork & SS5 & 0.724 & & & & & \\
& TW1 & 0.751 & 0.790 & 0.800 & 0.860 & 0.610 & 1.570 \\
& TW3 & 0.790 & & & & & \\
& TW4 & 0.755 & & & & & \\
\hline
\end{tabular}

In the last stage of assessing the measurement model, the discriminant validity between the three latent variables was estimated by Heterotrait-Monotrait (HTMT) ratio of correlations (Henseler, Ringle, \& Sarstedt, 2015). In fact, HTMT refers to "...the ratio of correlations within the constructs to correlations between the constructs.. an estimate of what the true correlation between two constructs would be if they are perfectly measured..". HTMT matrix may be assessed in two ways: in terms of HTMT criterion and in terms of HTMT inference. Following the suggested stringent HTMT criterion i.e. HTMT0.85 (Henseler et al., 2015; Kline, 2011), Table 3 shows that all HTMT ratio of correlations are less than 0.85 which indicates that the discriminant validity has been established between the three constructs of this study. Furthermore, a 5,000 complete bootstrapping method was executed to obtain the HTMT inference statistics for each of the HTMT criterion values (Hair Jr et al., 2017). Indeed, HTMT inference examines the statistical significance of the HTMT ratio of correlations at $95 \%$ confidence intervals bias corrected (CIBC). Since the confidence interval (as shown within a parenthesis in Table 3) does not show a value of 1 for any of the constructs, it suggests that the discriminant validity has been established in terms of HTMT inference too.

Table 3

Discriminant Validity using HTMT0.85 and HTMT Inference

\begin{tabular}{lccc}
\hline & $\begin{array}{c}\text { Employee } \\
\text { Performance }\end{array}$ & $\begin{array}{c}\text { Supervisor } \\
\text { Support }\end{array}$ & Teamwork \\
\hline Employee Performance & & & \\
Supervisor Support & 0.579 & & \\
& $(0.450-0.697)$ & & \\
Teamwork & 0.622 & 0.728 & \\
& $(0.499-0.731)$ & $(0.648-0.802)$ & \\
\hline
\end{tabular}




\section{Hypothesis Testing}

A PLS-SEM technique was applied to test hypotheses using consistent PLS algorithm with recommended 5,000 bootstrap resamples (Hair, Ringle, \& Sarstedt, 2013; Preacher \& Hayes, 2008), to estimate the direct effect of teamwork and supervisor support on employee performance (see Table 4). The results show that teamwork is statistically different from zero $(0.308, \mathrm{p}<0.001)$ which means that teamwork has a statistically significant effect on employee performance, thus $\mathrm{H} 1$ is supported.

Table 4

Hypothesis Testing

\begin{tabular}{lcccccc}
\hline Hypothesized Relationship & Estimate & SE & T & p-value & 95\% CIBC & Effect Size \\
\hline Teamwork $\rightarrow$ Employee Performance & 0.308 & 0.068 & 4.523 & $0.000^{* * *}$ & $0.199,0.421$ & 0.081 (Large) \\
$\begin{array}{l}\text { Moderation Analysis: } \\
\text { Supervisor Support } \rightarrow \text { Employee Performance }\end{array}$ & & & & & & \\
TW $*$ SS (Interaction) $\rightarrow$ Employee Performance & 0.132 & 0.07 & 3.771 & $0.000^{* * *}$ & $0.150,0.384$ & 0.064 (Large) \\
\hline
\end{tabular}

Notes: * 95\% CI $(\mathrm{p}<0.05) ; * * * 99.99 \%$ CI $(\mathrm{p}<0.001)$

Employee Performance: $R^{2}=0.276$; Adjusted $R^{2}=0.268$

Blindfolding $Q^{2}=0.201$

\section{Moderation Analysis}

In order to test whether supervisor support moderates the positive relationship between teamwork and employee performance $\left(\mathrm{H}_{2}\right)$, we followed the guidelines of Hair Jr et al. (2017). First of all, using PLS algorithm, an $R^{2}$ value was recorded in the absence of an interaction term (called $R^{2}$ excluded $=0.264$ ). Then an interaction term was created by using two-stage approach with standardized estimates because the primary concern was to disclose the statistical significance of the moderating effect. Again, using PLS algorithm, an $R^{2}$ value was recorded in the presence of the interaction term (called $R^{2}$ included $=0.276$ ). An effect size $\left(f^{2}\right)$ was then simply calculated by putting both $R^{2}$ values. According to more realistic standards suggested by Kenny (2016), the effect size of the interaction term was 0.017 which indicates a medium effect.

To investigate the size of the moderating effect, Table 4 shows that the interaction term has a positive effect on employee performance (0.132), whereas the simple effect of teamwork on employee performance is 0.308 . Jointly, these results suggest that the relationship between teamwork and employee performance is 0.308 for an average level of supervisor support. For higher levels of supervisor support (e.g., supervisor support is increased by one standard deviation unit), the relationship between teamwork and employee performance increases by the size of the interaction term (i.e., $0.308+0.132=0.440$ ). On the contrary, for lower levels of supervisor support (e.g., supervisor support is decreased by one standard deviation point), the relationship between teamwork and employee performance becomes $0.308-0.132=0.176$.

To better comprehend the results of the moderator analysis, we performed a simple slope analysis that plots the two-way interaction effect (Figure 2). The three lines shown in in Figure 2 represent the relationship between teamwork (on x-axis) and employee performance (on y-axis). More precisely, the middle line represents the relationship for an average level of the moderator variable 'supervisor support'. The other two lines repre- 
sent the relationship between teamwork and employee performance for higher (i.e., mean value of supervisor support plus one standard deviation unit) and lower (i.e., mean value of supervisor support minus one standard deviation unit) levels of the moderating variable 'supervisor support'. As we can see, the relationship between teamwork and employee performance is positive for all three lines as indicated by their positive slope. Hence, higher levels of teamwork go hand in hand with higher levels of employee performance which ultimately suggests that supervisor support moderates the positive relationship between teamwork and employee performance such that an increase in supervisor support would strengthen the positive relationship between teamwork and employee performance in the high-tech engineering SMEs of Karachi thus, $\mathrm{H}_{2}$ is also supported.

Figure 2

Simple Slop Analysis

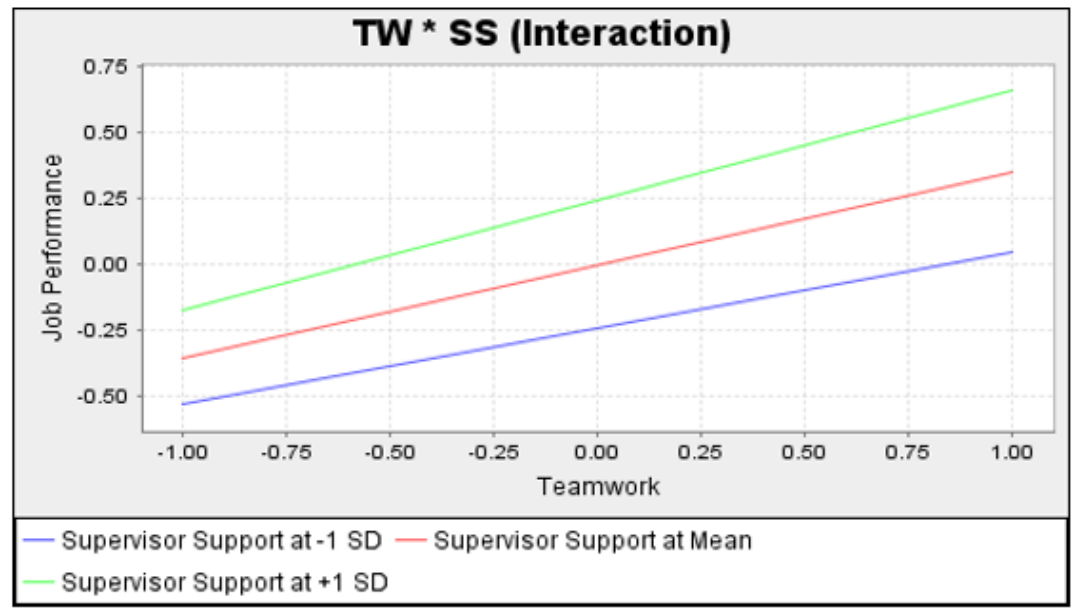

\section{Predictive Validity using PLSpredict}

Most recent literature on predictive validity (Shmueli et al., 2019) argued that the $R^{2}$ value only assesses the in-sample explanatory power without giving any indication of out-ofsample (OOS) predictive power of the structural model to predict new cases. Similarly, the blindfolding value $\left(Q^{2}=0.201\right)$ only omits and imputes single data points from within the sample to illustrate a combination of in-sample as well as OOS prediction without clearly suggesting the predictive validity (or power) of the structural model. In other words, $Q^{2}$ is considered as a partial or incomplete estimate of OOS predictive power (Nitzl \& Chin, 2017). Therefore, considering the methodological limitations of $R^{2}$ and $Q^{2}$ in explaining the predictive power of the structural model, we further applied PLSpredict procedure (Shmueli et al., 2019) in SmartPLS. It is "...a holdout-sample-based procedure that generates caselevel predictions on an item or a construct level to reap the benefits of predictive model assessment in PLS-SEM". The most important benefit of using PLSpredict is that the managerial implications can truly reflect the actual research findings of this empirical 
study when the structural model holds acceptable OOS predictive validity (power).

We followed the three-step decision tree diagram of PLSpredict procedure (Shmueli et al., 2019). Table 5 shows that the $Q^{2}$-predict value of the endogenous latent variable i.e. 'employee performance' and its observed indicators (EP4 and EP5) had positive values (greater than zero) indicating that the structural model holds sufficient predictive power. Then we assessed the degree of prediction error using the statistic of root mean squared error (RMSE) because the prediction errors (or residuals) of employee performance were highly symmetrically distributed (Figure 3 ).

Figure 3

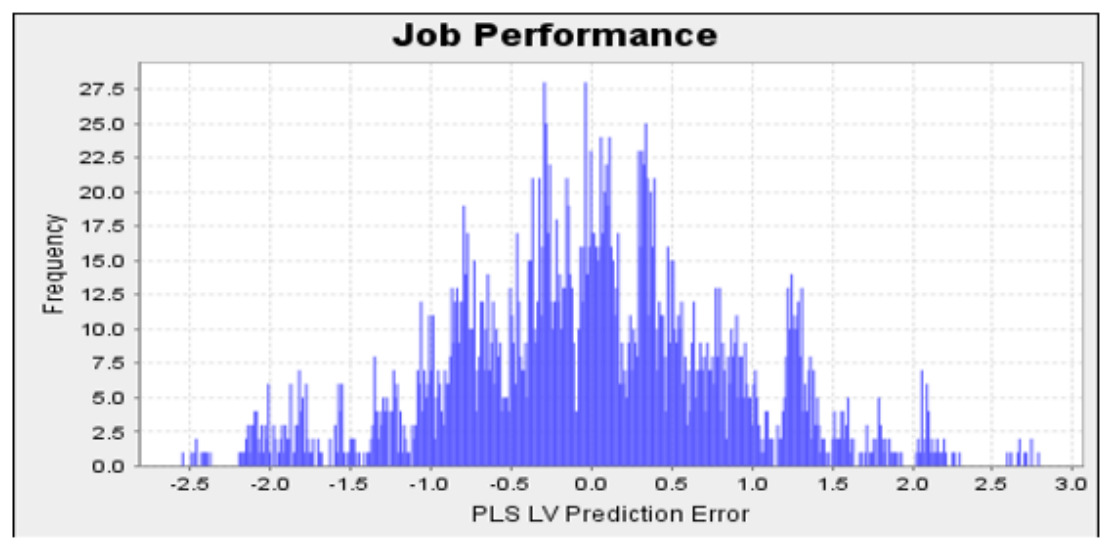

Finally, we compared the prediction errors (RMSE) of the PLS-SEM model with the prediction errors of the simple linear model (LM). Notably, the PLSpredict algorithm automatically creates the LM for the comparison purpose only. Table 5 shows that the RMSE value of PLS-SEM model are less than the RMSE value of LM for all of the two indicators (EP4 and EP5). It suggests that the PLS-SEM model of this study holds high OOS predictive validity or power (Shmueli et al., 2019).

Table 5

Predictive Power Using PLSpredict

\begin{tabular}{lccccc}
\hline Indicators & $\begin{array}{c}Q^{2} \text { _predict } \\
\text { (Indicators) }\end{array}$ & $\begin{array}{c}\text { RMSE } \\
\text { (PLS) }\end{array}$ & $\begin{array}{c}\text { RMSE } \\
(\mathbf{L M})\end{array}$ & $\begin{array}{c}\text { Is RMSE (PLS) } \\
\text { less than RMSE (LM)? }\end{array}$ & Decision \\
\hline EP4 & 0.189 & 0.743 & 0.760 & Yes & High OOS Predictive \\
EP5 & 0.190 & 0.759 & 0.772 & Yes & Validity or Power \\
\hline
\end{tabular}

\section{Discussion}

The first objective of this study was to analyze the effect of teamwork on employee performance. The results show that teamwork has a significant and positive effect on employee performance $\left(\beta=0.308 ; \mathrm{t}=4.523^{* * *}\right)$ in the high-tech engineering SMEs of Karachi. Besides, this relationship demonstrates an $f^{2}$ value of 0.081 which indicates a large effect 
size (Kenny, 2016). In fact, an effect size specifies the substantive (or practical) effect as an indication of a 'practical significance'. It may be defined as "...the magnitude of the result as it occurs, or would be found, in the population" (Ellis, 2010). In other words, an effect size denotes "the degree to which the phenomenon exists" (Cohen, 1992). Albeit, interpreting a p-value of hypothesis testing result is important, interpreting its effect size should be given more consideration suggested that "...the primary product of a research inquiry is one or more measures of effect size, not p values".

Indeed, the positive relationship between teamwork and employee performance is attributed to the fact that engineering firms operate a number of small and large scale projects which involve multiple teams, directions to meet strict deadlines, frequent vertical and horizontal communications with add-on work pressures. In the engineering firms, teams are usually composed of diverse range of talented people having varied academic and professional backgrounds. Undoubtedly, teamwork originates a useful platform for its members to share their novel and useful ideas. Some of these ideas may be materialized to further re-engineer organizational performance.

Unlike those who generally prefer to work in an isolation, employees who work in a team formation are exposed to different sets of skills and competencies exhibited by their team members. A major advantage of teamwork is the diversity of sharing ideas among team members which enables them to learn from other's mistakes and ineffective courses of actions. More precisely, when an organization strives to become an effective learning organization, it requires its managers to acquire, create and disseminate knowledge for the success of their organization (such as competitive advantage). Notably, knowledge involves appropriately processing the information available in hand which can be processed for useful business insights. Apparently, it seems easy to process information, but an effective teamwork can play a pivotal role in transforming information into useful knowledge because an effective teamwork can bring higher-quality performance than expected and it can substantially contribute in improving working conditions for others to excel at knowledge sharing and dissemination. Organizational teams with specialists having formal knowledge can substantially contribute towards organizational sustainability, effectiveness, and competitive advantage. In short, teamwork can bring useful results at both individual level as well as at organizational level provided that all of the organizational members establish a strong belief of its contribution and do not, what authors such as Haber (2016) opined, take it for granted in the larger goods of the organization.

In addition, the findings of $H_{2}$ indicate that supervisor support plays a significant role in strengthening the positive relationship between teamwork and employee performance. Employees generally observe their supervisor support in the form of their greater access to organizational tangible and intangible resources including external relationships. Bilateral relationship between team members and the leader is also enhanced with the improvement of employee performance. In majority of the scenarios, managers in engineering firms seek expert advices and opinions from specialized external consultants. In contrast, young team members might not have easy access to these expensive consultants however, a supervisor or business unit manager may arrange the exclusive consultancy services of these professionals for their team members.

Besides, supervisors additionally assume their dynamic job in settling any potential 
clashes in groups by connecting all colleagues in proactively accomplishing set targets and objectives on time. Supervisors ought to be in this manner, fill in as an 'umbrella' such that colleagues willfully perform their obligations and contribute in making and conveying aggregate 'esteem' for organization development. This incentive justifies itself with real evidence when a group meets the majority of its objectives effectively on time. By prudence of the external connections of the boss, a group could be in a situation to quicken in mastering skills in certain control in the designing process for example, item examination, plan, fabricating, testing, execution and training of users of their building items or frameworks. In short, supervisor support is observed to be an extremely valuable essential part in fortifying the positive connection between teamwork and task performance in the high-tech engineering SMEs of Karachi, Pakistan.

\section{Managerial Implications}

With large effect sizes, this study does not only reveal a significant effect of teamwork on employee performance but also shows that this positive relationship could be further strengthened for those who reported higher level of supervisor support. Thus, these research findings lead us to suggest a number of managerial implications as under. First of all, the top management of high-tech engineering SMEs need to realize that work teams are generally composed of a diverse range of members with varying occupational and emotional needs. These team members can only perform up to the desired level if both sets of their needs are appropriately satisfied on time. Moreover, it is also mandatory to realize its significance because teams are interconnected with each other such that a negative word-of-mouth tends to travel much faster than positive management deeds. For instance, assume that a young inexperienced member of a team places a request to her management for a job-related training which is turned down by her management by giving her such excuses which are indeed within the capacity of the management. The management refused to send her on the required training sessions having an established belief that training is generally turn out to be an expense in their organization. It is because in the past, employees completed their expensive training sessions, immediately quit their jobs and started to provide the benefits of the training to the rival companies. In short, the management perceives training is an expense rather than an investment. The demoralized team player will therefore be less likely to perform than expected and sooner or later, she is going to discuss causes of her low performance with others. Following the attribution theory (Weiner, 1986), she may be more aggressive by attributing the causes of her low performance towards the pejorative behaviour of her management which did not facilitate her on time in learning necessary skills through the training sessions she requested. The management should not generalize their perception built as a result of the unpleasant work behaviour of past employees on to the present team members. In addition, knowing the fact that some employees are more comfortable while working in isolation, engineering firms should give them space and also involve them in such a manner that they could holistically contribute in teams to achieve team's goals and eventually, annual targets of their functional area.

Besides, it is equally important for the top management to realize the practical significance of tangible and/or intangible support from a supervisor in strengthening the closed 
bond between teamwork and task performance. Tangible resources include the physical resources which are essential for any business to function properly, whereas intangible resources comprise of facilitation which may strengthen the smooth functioning of a business operation such as an organizational climate with zero-tolerance of sexual harassment, uncivil behaviour, etc. Undoubtedly, both tangible and intangible sets of resources are much needed as a collective facilitation for all functional teams because failure to manage these sets of resources could result in unpleasant organizational consequences such as financial distress due to low market share, high employee turnover, and above all, the dying hope of numerous families attached these employees whose better and progressive career expectations were dependent on the occupational growth of these employees.

In addition, senior managers of high-tech engineering SMEs should also take some necessary measures such as they should contribute to the overall work of teams by identifying and extending their appropriate assistance to a team member in order to address any difficulty at work. Besides, they should interact with team members by showing a keen interests in their emerging ideas and encourage them for better results on time. Moreover, they should also keep the teams on track by carefully watching working conditions, and also provide them constructive feedback on time. Harnessing the principle of Pygmalion effect (Eden, 1984) which suggests that expectations lead to performance, they should sufficiently raise their expectations from their teams for better quality of work and higher performance.

\section{Theoretical Implications}

This study extends the generalizability of the positive relationship between teamwork and employee performance to the high-tech engineering SMEs of Pakistan. In addition, it argues that this relationship can strengthen for those employees who report higher level of support from their supervisors. In short, both findings are consistent with past studies, however, both of them are very much new empirical findings in the said research context because this is perhaps the first report of its nature in the developing country such as Pakistan.

\section{Conclusion}

The 21st century has started to give much attention on the ways through which SMEs can gain a competitive advantage through their employee performance. A high-performing market-driven business organization has a strong belief in its human capital and confidently invests in its people for their personal as well as organizational growth and success. This study makes a small attempt to reiterate the theoretical relationship between teamwork, supervisor support, and employee performance together in one empirical study specifically in the context of a rarely-tested business sector of Pakistan. The phenomenon of improving employee performance has been one of the most important and very serious issues in engineering SMEs of Karachi due to the indispensable involvement of the state-of-theart computer-integrated manufacturing (CIM) technologies. Furthermore, it was argued that employees should be encouraged to work in a team formation so that they could 
pragmatically contribute their organization in gaining a sustainable competitive advantage in the marketplace and/or marketspace. We maintain that an enabling organizational culture should be in place to materialize employees' potential into meaningful results on time. At the end, it is believe that this study opens new avenues for basic and applied research in other under-studied business sectors of Pakistan and other developing countries.

\section{Limitations and Directions for Future Studies}

The following limitations should be taken into consideration while interpreting the results. First, this is a cross-sectional examination in the largest city of Pakistan which precludes the generalizability of the findings on other industries. Future researchers should prefer to develop a longitudinal study with other geographical locations of Pakistan which have a high influx of manufacturing and engineering companies such as Lahore, Sialkot, Multan, etc. Second, this study used only one moderator i.e. supervisor support, however, there could be other boundary conditions which may also strengthen the positive relationship between teamwork and employee performance such as climate of informality (Schilpzand, De Pater, \& Erez, 2016), economic LMX (Berg, Grimstad, Škerlavaj, \& Černe, 2017), felt obligation (Pan, Sun, \& Chow, 2012), team-member exchange - TMX (Seers, 1989) etc. For instance, a very little is known how TMX (Banks et al., 2014) could possibly moderate the positive relationship between teamwork and extra-role performance. Similarly, it would also significantly contribute in the existing body of literature of employee performance if the moderating role of workplace mistreatment variables (such as ostracism) is empirically examined in both the manufacturing as well as in the service organizations. Finally, this study collected a self-report measure of employee performance, whereas future studies may collect nested (or hierarchical) data having supervisor-rated employee performance with dyadic unit of analysis and hypotheses may be tested using a multilevel modelling (MLM) instead of using either variance- or covariance-based SEM technique. 


\section{References}

Adil, M. S. (2014). Impact of leader's change-promoting behavior on readiness for change: A mediating role of organizational culture. Journal of Management Sciences, 1(2), $102-123$.

Adil, M. S. (2015). Strategic human resource management practices and competitive priorities of the manufacturing performance in Karachi. Global Journal of Flexible Systems Management, 16(1), 37-61.

Adil, M. S. (2016). Impact of change readiness on commitment to technological change, focal, and discretionary behaviors. Journal of Organizational Change Management.

Adil, M. S., \& Awais, A. (2016). Effects of leader-member exchange, interpersonal relationship, individual feeling of energy and creative work involvement towards turnover intention: A path analysis using structural equation modeling. Asian Academy of Management Journal, 21(2), 99-133.

Ahmad, I., Manzoor, S. R., et al. (2017). Effect of teamwork, employee empowerment and training on employee performance. International Journal of Academic Research in Business and Social Sciences, 7(11), 380-394.

Ancona, D. G. (1996). Managing for the future: Organizational behavior and processes. Cincinnati, OH: Massachusetts Institute of Technology/South-Western Publishing.

Andersson, L. M., \& Bateman, T. S. (1997). Cynicism in the workplace: Some causes and effects. Journal of Organizational Behavior: The International Journal of Industrial, Occupational and Organizational Psychology and Behavior, 18(5), 449-469.

Andrews, M., \& Smits, S. (2019). Using tacit knowledge exchanges to improve teamwork. ISM Journal of International Business, 3(1), 15-23.

Banks, G. C., Batchelor, J. H., Seers, A., O’Boyle Jr, E. H., Pollack, J. M., \& Gower, K. (2014). What does team-member exchange bring to the party? A meta-analytic review of team and leader social exchange. Journal of Organizational Behavior, $35(2), 273-295$.

Bell, S. J., \& Menguc, B. (2002). The employee-organization relationship, organizational citizenship behaviors, and superior service quality. Journal of Retailing, 78(2), 131146.

Berg, S. T. S., Grimstad, A., Škerlavaj, M., \& Černe, M. (2017). Social and economic leader-member exchange and employee creative behavior: The role of employee willingness to take risks and emotional carrying capacity. European Management Journal, 35(5), 676-687.

Chaubey, A., Sahoo, C. K., \& Khatri, N. (2019). Relationship of transformational leadership with employee creativity and organizational innovation. Journal of Strategy and Management, 12(1), 61-82.

Chen, T., Hao, S., Ding, K., Feng, X., Li, G., \& Liang, X. (2019). The impact of organizational support on employee performance. Employee Relations: The International Journal, 42(1), 166-179.

Cohen, J. (1992). Things i have learned (so far). American Psychologist, 45(12), 13041312. 
Corritore, M., Goldberg, A., \& Srivastava, S. B. (2020). The new analytics of culture. Harvard Business Review, 98(1), 76-83.

Dinh, J. V., Traylor, A. M., Kilcullen, M. P., Perez, J. A., Schweissing, E. J., Venkatesh, A., \& Salas, E. (2020). Cross-disciplinary care: A systematic review on teamwork processes in health care. Small Group Research, 51(1), 125-166.

Dixon, D. P., Weeks, M., Boland Jr, R., \& Gaskin, J. (2019). In extremis leadership: A study of the effects in different contexts. American Journal of Management, 19(3), $35-63$.

Eisenberger, R., Huntington, R., Hutchison, S., \& Sowa, D. (1986). Perceived organizational support. Journal of Applied Psychology, 71(3), 500-507.

Ellis, P. D. (2010). The essential guide to effect sizes: Statistical power, meta-analysis, and the interpretation of research results. Cambridge, UK: Cambridge University Press.

Falahat, M., Ramayah, T., Soto-Acosta, P., \& Lee, Y.-Y. (2020). SMEs internationalization: The role of product innovation, market intelligence, pricing and marketing communication capabilities as drivers of SMEs' international performance. Technological Forecasting and Social Change, 152. doi: 10.1016/j.techfore.2020.119908

Glaser, S. R., Zamanou, S., \& Hacker, K. (1987). Measuring and interpreting organizational culture. Management Communication Quarterly, 1(2), 173-198.

Gully, S. M., Devine, D. J., \& Whitney, D. J. (1995). A meta-analysis of cohesion and performance: Effects of level of analysis and task interdependence. Small Group Research, 26(4), 497-520.

Haber, J. (2016). Institutionalized involvement: Teams and stress in 1990s US steel. Industrial Relations: A Journal of Economy and Society, 55(4), 632-661.

Hagiu, A., \& Wright, J. (2020). When data creates competitive advantage. Harvard Business Review, 98(1), 94-101.

Hair, J. F., Black, W. C., Babin, B. J., Anderson, R. E., \& Tatham, R. L. (2019). Multivariate data analysis. Hampshire, UK: Cengage Learning EMEA.

Hair, J. F., Ringle, C. M., \& Sarstedt, M. (2013). Partial least squares structural equation modeling: Rigorous applications, better results and higher acceptance. Long Range Planning, 46(1-2), 1-12.

Hair Jr, J. F., Hult, G. T. M., Ringle, C., \& Sarstedt, M. (2017). A primer on partial least squares structural equation modeling (PLS-SEM). CA: Sage, Thousand Oaks.

Hauptman, O., \& Hirji, K. K. (1996). The influence of process concurrency on project outcomes in product development: An empirical study of cross-functional teams. IEEE Transactions on Engineering Management, 43(2), 153-164.

Henseler, J., Ringle, C. M., \& Sarstedt, M. (2015). A new criterion for assessing discriminant validity in variance-based structural equation modeling. Journal of the Academy of Marketing Science, 43(1), 115-135.

Hoegl, M., \& Parboteeah, K. P. (2007). Creativity in innovative projects: How teamwork matters. Journal of Engineering and Technology Management, 24(1-2), 148-166.

Hughes, A. M., Gregory, M. E., Joseph, D. L., Sonesh, S. C., Marlow, S. L., Lacerenza, C. N., ... Salas, E. (2016). Saving lives: A meta-analysis of team training in healthcare. Journal of Applied Psychology, 101(9), 1266-1304.

Jaramillo, F., Ladik, D. M., Marshall, G. W., \& Mulki, J. P. (2007). A meta-analysis of the 
relationship between sales orientation-customer orientation (SOCO) and salesperson job performance. Journal of Business $\&$ Industrial Marketing, 22(5), 302-310.

Kenny, D. A. (2016). Moderation. Retrieved from davidakenny.net/cm/moderation.htm

Kichuk, S. L., \& Wiesner, W. H. (1997). The big five personality factors and team performance: Implications for selecting successful product design teams. Journal of Engineering and Technology Management, 14(3-4), 195-221.

Kline, R. B. (2011). Principles and practice of structural equation modeling. New York: The Guilford Press.

Kock, N. (2015). Common method bias in PLS-SEM: a full collinearity assessment approach. International Journal of e-Collaboration, 11(4), 1-10.

Lin, H.-F., \& Lee, G.-G. (2004). Perceptions of senior managers toward knowledge-sharing behaviour. Management Decision, 42(1), 108-125.

Masterson, S. S. (2001). A trickle-down model of organizational justice: Relating employees' and customers' perceptions of and reactions to fairness. Journal of Applied Psychology, 86(4), 594-604.

Mijakoski, D., Karadzhinska-Bislimovska, J., Stoleski, S., Minov, J., Atanasovska, A., \& Bihorac, E. (2018). Job demands, burnout, and teamwork in healthcare professionals working in a general hospital that was analysed at two points in time. Open Access Macedonian Journal of Medical Sciences, 6(4), 723-729.

Molina, L. M., Lloréns-Montes, J., \& Ruiz-Moreno, A. (2007). Relationship between quality management practices and knowledge transfer. Journal of Operations Management, $25(3), 682-701$.

Mulki, J. P., Caemmerer, B., \& Heggde, G. S. (2015). Leadership style, salesperson's work effort and job performance: The influence of power distance. Journal of Personal Selling 8 Sales Management, 35(1), 3-22.

Nitzl, C., \& Chin, W. W. (2017). The case of partial least squares (PLS) path modeling in managerial accounting research. Journal of Management Control, 28(2), 137-156.

Pan, W., Sun, L.-Y., \& Chow, I. H. S. (2012). Leader-member exchange and employee creativity: Test of a multilevel moderated mediation model. Human Performance, $25(5), 432-451$.

Porter, M. E. (2008). On competition. Boston: Harvard Business School Publishing.

Porter, M. E., \& Guth, C. (2012). Redefining German health care: Moving to a value-based system. Heidelberg: Springer.

Preacher, K. J., \& Hayes, A. F. (2008). Asymptotic and resampling strategies for assessing and comparing indirect effects in multiple mediator models. Behavior Research Methods, 40(3), 879-891.

Rapp, A., Ahearne, M., Mathieu, J., \& Schillewaert, N. (2006). The impact of knowledge and empowerment on working smart and working hard: The moderating role of experience. International Journal of Research in Marketing, 23(3), 279-293.

Reio Jr, T. G. (2010). The threat of common method variance bias to theory building. Human Resource Development Review, 9(4), 405-411.

Rhoades, L., \& Eisenberger, R. (2002). Perceived organizational support: A review of the literature. Journal of Applied Psychology, 87(4), 698-714.

Ringle, C. M., Wende, S., \& Becker, J.-M. (2015). SmartPLS 3. Bönningstedt: SmartPLS. 
Schilpzand, P., De Pater, I. E., \& Erez, A. (2016). Workplace incivility: A review of the literature and agenda for future research. Journal of Organizational behavior, 37, $57-88$.

Seers, A. (1989). Team-member exchange quality: A new construct for role-making research. Organizational Behavior and Human Decision Processes, 43(1), 118-135.

Shmueli, G., Sarstedt, M., Hair, J. F., Cheah, J.-H., Ting, H., Vaithilingam, S., \& Ringle, C. M. (2019). Predictive model assessment in PLS-SEM: guidelines for using PLSpredict. European Journal of Marketing.

Sull, D. N. (2005). Why good companies go bad. Financial Times, 77(4), 42-50.

Teclemichael Tessema, M., \& Soeters, J. L. (2006). Challenges and prospects of HRM in developing countries: Testing the HRM-performance link in the Eritrean civil service. The International Journal of Human Resource Management, 17(1), 86-105.

Tepper, B. J., \& Taylor, E. C. (2003). Relationships among supervisors' and subordinates' procedural justice perceptions and organizational citizenship behaviors. Academy of Management Journal, 46(1), 97-105.

Wayne, S. J., Shore, L. M., \& Liden, R. C. (1997). Perceived organizational support and leader-member exchange: A social exchange perspective. Academy of Management Journal, 40(1), 82-111.

Weiner, B. (1986). An attributional theory of motivation and emotion. New York: SpringerVerlag. 